\title{
On the time course of letter perception: A masked priming ERP investigation
}

\author{
JEAN-PHILIPPE PETIT \\ CNRS and Université de Provence, Marseille, France \\ KATHERINE J. MIDGLEY \\ CNRS and Université de Provence, Marseille, France \\ and Tufts University, Medford, Massachusetts \\ PHILLIP J. HOLCOMB \\ Tufts University, Medford, Massachusetts \\ and \\ JONATHAN GRAINGER \\ CNRS and Université de Provence, Marseille, France
}

\begin{abstract}
In an experiment measuring event-related brain potentials (ERPs), single-letter targets were preceded by briefly presented masked letter primes. Name and case consistency were manipulated across primes and targets so that the prime was either the same letter as the target (or not), and was presented in the same case as the target (or not). Separate analyses were performed for letters whose upper- and lowercase forms had similar features (or not). The results revealed an effect of prime-target visual similarity between 120 and $180 \mathrm{msec}$, an effect of case-specific letter identity between 180 and $220 \mathrm{msec}$, and an effect of case-independent letter identity between 220 and $300 \mathrm{msec}$. We argue that these ERP results reflect processing in a hierarchical system for letter recognition that involves both case-specific and case-independent representations of alphabetic stimuli.
\end{abstract}

Prior research using the masked priming paradigm has provided important information concerning the precise mechanisms involved in letter perception (see, e.g., Jacobs $\&$ Grainger, 1991). The present study combines masked priming and the temporal sensitivity of event-related potentials (ERPs) to test predictions derived from a model of the dynamics of letter perception.

Studies using the letter-naming task have generally shown that masked priming effects are mostly driven by primetarget name consistency, and depend little on visual similarity (Arguin \& Bub, 1995; Bowers, Vigliocco, \& Haan, 1998; Ziegler, Ferrand, Jacobs, Rey, \& Grainger, 2000). For example, priming effects are practically as strong for visually dissimilar lower- and uppercase versions of a given letter (e.g., g-G) as they are with more similar combinations (e.g., c-C), and this is true even when the prime is formed from parts of the opposite-case version of the target letter, such as midsegments (Petit \& Grainger, 2002). This result

The authors thank Guy Farnarier, APHM, for help in running the pilot work for this study. The first author was supported by a grant from the French Ministry of Education. P.J.H. and K.J.M. were supported by NICHD Grants HD2589 and HD04351. Correspondence concerning this article should be addressed to J. Grainger, Laboratoire de Psychologie Cognitive, Université de Provence, 3 Pl. Victor Hugo, 13331 Marseille, France (e-mail: grainger@up.univ-mrs.fr). has been taken as evidence for the existence of abstract letter representations that disregard letter shape information (Arguin \& Bub, 1995).

Evidence for sensitivity to visual form in letter perception has been found using the alphabetic decision task (e.g., real letters vs. nonalphabetic characters; Bowers et al., 1998; Jacobs \& Grainger, 1991; Jacobs, Grainger, \& Ferrand, 1995; Ziegler et al., 2000). In these studies, stronger priming arises across lower- and uppercase versions of the same letter when they are visually similar $(\mathrm{c}-\mathrm{C})$ than when they are visually dissimilar $(\mathrm{g}-\mathrm{G})$. Together, these results provide some initial constraints for attempts to describe a computational model of letter perception.

Our working model of letter perception is described verbally within the general framework of interactive activation (McClelland \& Rumelhart, 1981) and the extension of that model to isolated letter perception (Jacobs \& Grainger, 1991). It is heavily inspired by the "pandemonium" model of Selfridge and Neisser (1960), as well as recent evidence from neuroimaging studies of the functional specialization of brain areas for visual perception (see Dehaene, Cohen, Sigman, \& Vinckier, 2005, for a similar approach applied to visual word recognition). This model minimally consists of three processing stages:

1. Subletter features. Early visual processing leads to the extraction of elementary visual features (e.g., lines of different orientation and curvature). At this level, process- 
ing is sensitive to the physical characteristics of stimuli, such as size, orientation, and component features.

2. Case-specific letter representations. Specific combinations of elementary visual features converge on higher level representations of letter form that are insensitive to variation in size and orientation. At this level, processing is sensitive to letter case (this is because many lower- and uppercase versions of the same letter have distinct visual forms).

3. Case-independent letter representations. Activation in case-specific letter representations is further propagated to more abstract representations that code the shared nominal identity of different letter forms. Hence, at this level, processing is insensitive to variation in visual form across a given letter identity.

In the present study, ERPs were recorded while participants performed a letter identification task in which they were cued on a randomly distributed small number of trials $(17 \%)$ to report the target letter they had just seen. On the majority of trials, the participants passively viewed the target letter without providing an overt response. In this way, ERPs to target letters were not contaminated by possible activity generated by the execution of a motor response. All target letters were clearly visible and immediately preceded by forward- and backward-masked, briefly presented prime letters. Name and case were manipulated across primes and targets so that the prime letters were either the same letter or a different letter than the following target (name consistency), and were presented in either the same case or the opposite case from the following target (case consistency).

ERPs have already been successfully applied in combination with the masked priming paradigm in recent investigations of visual word recognition (Holcomb \& Grainger, 2006; Holcomb, Reder, Misra, \& Grainger, 2005; Kiyonaga, Grainger, Midgley, \& Holcomb, in press; Misra \& Holcomb, 2003; Schnyer, Allen, \& Forster, 1997). In these studies, repetition effects on targets following masked primes produced a modulation of the $\mathrm{N} 400$ (interpreted as a measure of late word and/or semantic processing), and in several others (Eddy, Schmid, \& Holcomb, in press; Holcomb \& Grainger, 2006; Kiyonaga et al., in press), modulations of earlier ERP components including a very early effect that started around $100 \mathrm{msec}$ posttarget onset and had a right occipital maximum. This "P150" effect was sensitive to physical differences between prime and target stimuli. Together, these studies illustrate one of the primary strengths of ERPs: They are sensitive to the early time course of both perceptual and cognitive processes and are not dependent on an overt behavioral response.

Based on the three-stage processing model outlined above, and prior ERP work with picture and word stimuli (Eddy et al., in press; Holcomb \& Grainger, 2006), we predicted that the P150 would prove sensitive to processing at the subletter feature level. The problem in testing this hypothesis is that to get sufficiently different features usually requires a manipulation of either letter name or case (i.e., differences in name and case are confounded with differences in visual similarity). To avoid this problem, in a separate follow-up analysis, we contrasted prime-target letter pairs of the same name and manipulated the similarity of the upper- and lowercase versions of the letters. For these comparisons, we chose the eight letters with the greatest number of common features for their upper- and lowercase versions $(\mathrm{C}-\mathrm{c}, \mathrm{O}-\mathrm{o}, \mathrm{S}-\mathrm{s}, \mathrm{U}-\mathrm{u}, \mathrm{V}-\mathrm{v}, \mathrm{W}-\mathrm{w}, \mathrm{X}-$ $\mathrm{x}, \mathrm{Z}-\mathrm{z}$ ) and contrasted them with the eight letters with the greatest number of feature differences between their upper- and lowercase versions (A-a, B-b, D-d, E-e, G-g, $\mathrm{N}-\mathrm{n}, \mathrm{Q}-\mathrm{q}, \mathrm{R}-\mathrm{r}$ ), based on the ratings of two independent judges. If the P150 effect is sensitive to feature level processing, then it should be significantly larger for dissimilar target letters following their same-name primes (e.g., D-d or d-D), compared with highly similar target letters following their primes (e.g., S-s or s-S).

Concerning the next two stages of our model of letter perception, it seems reasonable to predict that ERP effects of case-specific letter identity should follow the earlier P150 feature-extraction process, but precede any later, more abstract (case-insensitive) letter name activity. Our predictions relative to these two stages of processing in letter identification are best expressed in terms of the effects of name consistency (whether or not the prime is the same letter as the target) and its interaction with case consistency (whether or not the prime letter is in the same case as the target). The presence of an interaction is hypothesized to reflect processing at the level of casesensitive letter representations, with effects of name consistency arising only when primes and targets are in the same case. We expect case-sensitive letter representations to be primed mostly by the same letter in the same case (A-A) and much less by the same letter in the opposite case $(\mathrm{a}-\mathrm{A})$. On the other hand, a main effect of name consistency and no interaction would reflect processing at the level of case-insensitive letter representations, where we expect practically the same amount of priming when primes are in the same case (A-A) or different case (a-A), compared with targets. Our theoretical framework predicts that the case-sensitive pattern (an interaction between name consistency and case consistency) should appear earlier than the case-insensitive pattern (a main effect of name consistency).

\section{METHOD}

\section{Participants}

Twenty-four right-handed (14 female, 10 male, mean age $=$ 22.8 years), native French-speaking undergraduates at the University of Provence participated in the experiment as volunteers. All of the participants reported normal or corrected-to-normal vision.

\section{Stimuli}

The target letters were the 26 letters of the Roman alphabet. Prime-target relatedness was manipulated via two main factors: name consistency (the prime was nominally identical to the target letter or not) and case consistency (the prime and the target were in the same case or not). For half of the participants, when the prime and the target were in a different case, it was always the prime that was in lowercase, and for the other half, it was the target that was in lowercase. This resulted in four priming conditions: (1) Same letter/same case (A-A); (2) same letter/different case (a-A or A-a); 


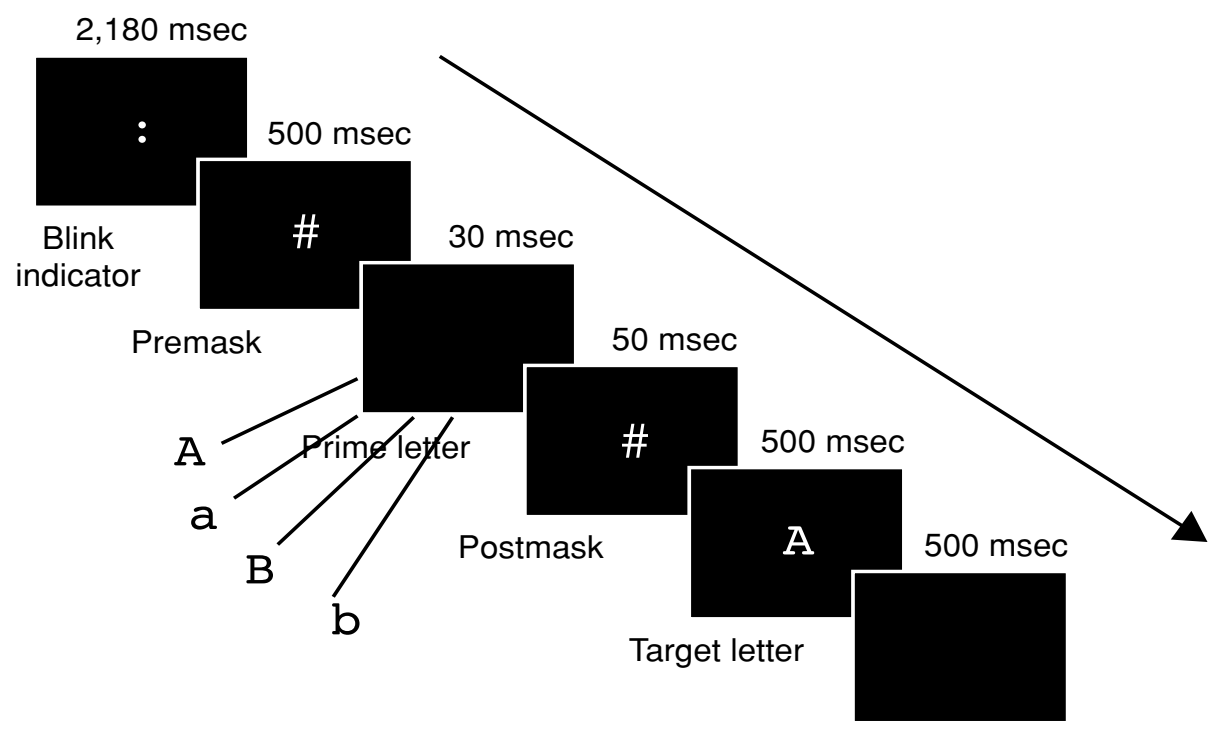

Figure 1. A typical trial.

(3) different letter/same case (B-A); and (4) different letter/different case $(b-A$ or $B-a)$. Each of the target letters was presented five times in each of the four prime conditions, giving a total of 520 trials per participant.

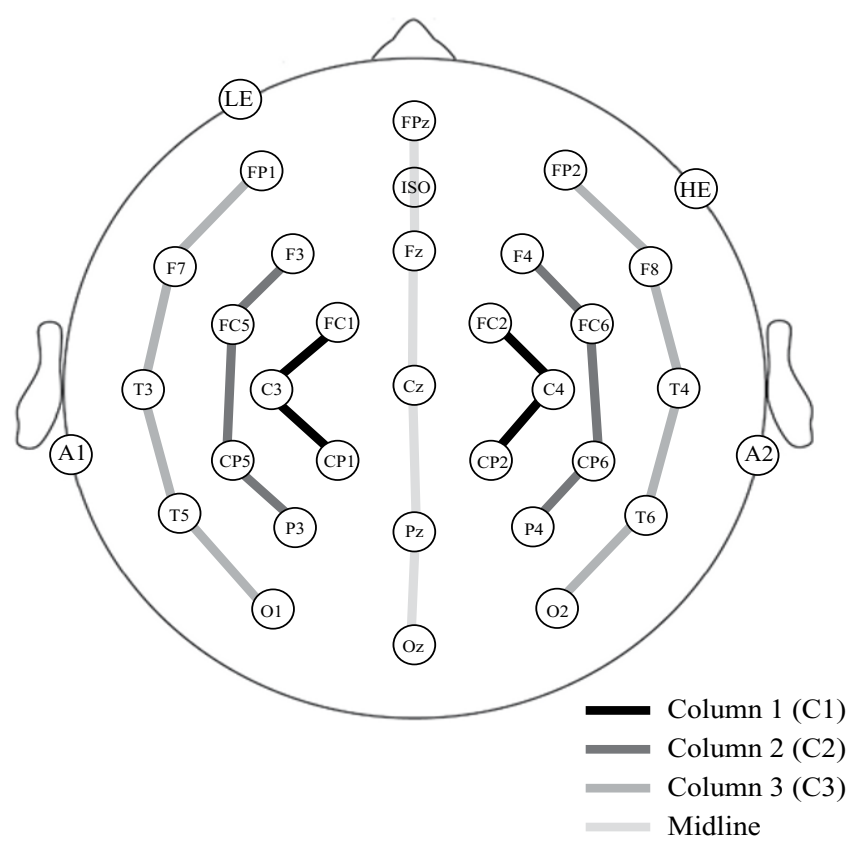

Figure 2. Electrode montage and analysis columns. Twenty-nine active tin electrodes were held in place by an elastic cap (ElectroCap International, Inc., Eaton, $\mathrm{OH})$ and maintained $<5 \mathrm{~K} \Omega$. Additional electrodes were placed below the left eye (LE) and beside the right eye (HE) to monitor eye movements and blinks. All electrodes were referenced to the left mastoid (A1), and the right mastoid (A2) was recorded actively to detect left/right mastoid asymmetry (none was detected). The four analysis columns (C1, $\mathrm{C2}, \mathrm{C3}$, and midline) are indicated by the gray bars interconnecting the various anterior/posterior sites.

\section{Procedure}

Stimulus presentation was synchronized to the vertical retrace of the computer's video card. Letter stimuli were presented in Courier font and each letter was $1 \times 0.9 \mathrm{~cm}$, giving a visual angle of about $0.72^{\circ}$ vertically and $0.64^{\circ}$ horizontally. Primes and targets were presented in the center of the screen, at high contrast, in white on a black background, and in a darkened room. The sequence and timing of events for each trial were as indicated in Figure 1.

Every six trials, on average, the trial sequence was followed by a "recall" signal ("?") that was displayed on the center of the screen and remained until the participants pressed the key corresponding to the target letter they had just seen. The EEG signal was recorded from electrodes attached to the scalp (see Figure 2), was amplified with a bandpass of 0.01 to $40 \mathrm{~Hz}$ (3-dB cutoffs), and was continuously digitized at $200 \mathrm{~Hz}$.

Data analysis. Averaged ERPs were formed offline from trials that were free of artifact, and time-locked to the onset of target letters. In the main analysis, 26 target letters were averaged into four conditions reflecting the factorial combination of two factors: prime-target name consistency (same name vs. different name) and prime-target case consistency (same case vs. different case). Averaged ERPs were quantified by calculating the mean amplitude values (relative to a $100-\mathrm{msec}$ pretarget baseline) in three different time windows: $120-180 \mathrm{msec}, 180-240 \mathrm{msec}$, and $240-300 \mathrm{msec}$. Separate sets of repeated measures ANOVAs (Greenhouse \& Geisser, 1959) were run on the data from each of the three mean amplitude windows. Each analysis included four separate subanalyses aimed at carefully evaluating distributional effects in the ERPs. In three analyses of sites over the two hemispheres ( $\mathrm{C} 1, \mathrm{C} 2$, and $\mathrm{C} 3$ ), there was a factor of anterior/posterior electrode site and a second factor of hemisphere (left vs. right; see Figure 2). A fourth "midline" analysis included a single anterior/posterior electrode site factor.

\section{RESULTS}

The participants correctly identified $97.9 \%$ of the target letters on recall trials. The grand average ERPs, timelocked to target letters for the four critical conditions at the 29 scalp sites and the right mastoid, are shown in Figure $3 \mathrm{~A}$. Figure $3 \mathrm{~B}$ is a blowup of one site from Figure 3A. 

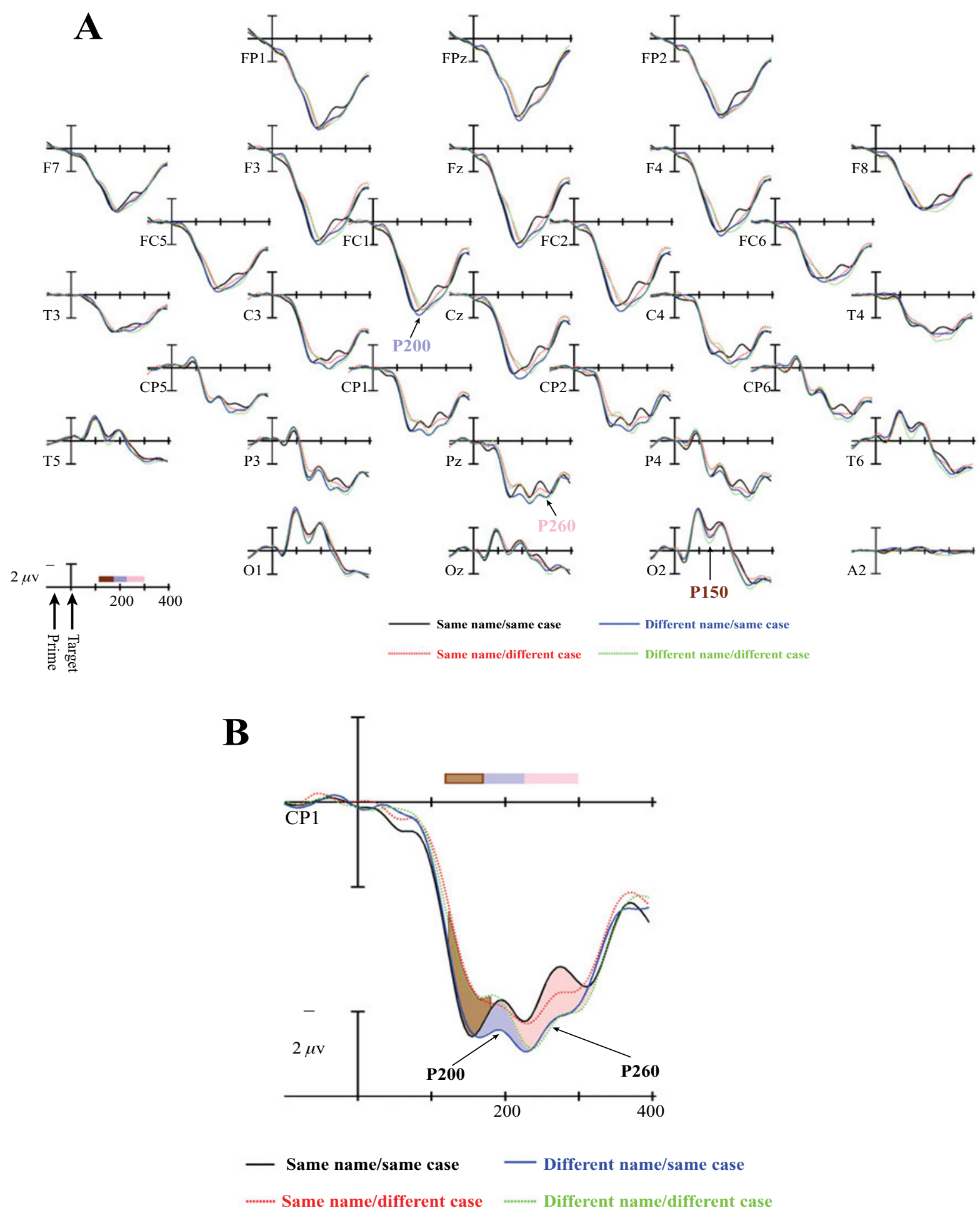

Figure 3. (A) Target ERPs from the four all letter scheme conditions. Note that the time intervals for analysis as well as prime and target onset latencies are indicated on the time axis in the lower left-hand corner and that target onset is indicated by the calibration bar. (B) Target ERPs at the CP1 electrode site for the four all letter scheme conditions. The three analysis epochs are color coded and the two primary ERP components analyzed are labeled. In the first epoch (brown) there are clear effects of letter case. At the beginning of the second epoch (blue) the same-name/same-case condition undergoes a much stronger deflection than any of the other conditions. In the third epoch (pink), the different-name conditions (for same and different case) start to pattern together and are clearly distinct from both of the same-name conditions. 
Table 1

Mean Microvolt Values (SEs) at the CP1 Site for the Name and Case Factors

\begin{tabular}{|c|c|c|c|c|c|c|c|c|}
\hline \multirow[b]{3}{*}{ Time Epoch (msec) } & \multicolumn{4}{|c|}{ Same Name } & \multicolumn{4}{|c|}{ Different Name } \\
\hline & \multicolumn{2}{|c|}{$\begin{array}{l}\text { Same } \\
\text { Case }\end{array}$} & \multicolumn{2}{|c|}{$\begin{array}{c}\text { Different } \\
\text { Case }\end{array}$} & \multicolumn{2}{|c|}{$\begin{array}{l}\text { Same } \\
\text { Case }\end{array}$} & \multicolumn{2}{|c|}{$\begin{array}{c}\text { Different } \\
\text { Case }\end{array}$} \\
\hline & $M$ & $\overline{S E}$ & $M$ & $\overline{S E}$ & $M$ & $\overline{S E}$ & $M$ & $S E$ \\
\hline $120-180$ & 4.89 & .43 & 3.91 & .43 & 4.91 & .41 & 4.12 & .36 \\
\hline $180-220$ & 4.82 & .54 & 4.90 & .55 & 5.49 & .55 & 4.88 & .51 \\
\hline $220-300$ & 4.42 & .55 & 4.79 & .54 & 5.35 & .62 & 5.35 & .55 \\
\hline
\end{tabular}

Table 1 provides mean voltage values per experimental condition at one representative electrode site (CP1) for each epoch used in the ANOVAs.

\section{0- to 180-msec Epoch}

As can be seen in Figures $3 \mathrm{~A}$ and 3B, there is a clear difference between target ERPs recorded to letter targets preceded by primes in the same case compared with targets preceded by primes in the other case. This difference starts as early as $110 \mathrm{msec}$ and continues until almost $200 \mathrm{msec}$ (see the brown shaded area in Figure 3B). This visual impression was confirmed by a significant main effect of case consistency in all four electrode columns [midline, $F(1,22)=21.97, p<.001 ; \mathrm{C} 1, F(1,22)=22.48, p<$ $.001 ; \mathrm{C} 2, F(1,22)=16.41, p<.001 ; \mathrm{C} 3, F(1,22)=5.19$, $p<.033]$. This effect tended to be larger at frontocentral sites, as indicated by significant case consistency $\times$ electrode site interactions [midline, $F(4,88)=10.48, p<$ $.001 ; \mathrm{C} 1, F(2,44)=8.04, p<.003 ; \mathrm{C} 2, F(3,66)=10.30$, $p<.002$; C3, $F(4,88)=15.19, p<.001]$. There were, however, no main effects of name consistency or interactions between case consistency and name consistency in this analysis epoch. This pattern is evident in the mean voltage values provided in Table 1 , and is in line with our prediction that processing has not yet made contact with letter representations at this point in time. ${ }^{1}$

To more fully scrutinize the effects of visual similarity in this early epoch, subsets of letters were classified according to whether their upper- and lowercase versions were visually similar (e.g., $\mathrm{C}-\mathrm{c}$ and $\mathrm{O}-\mathrm{o}$ ) or visually different (e.g., A-a and B-b). In this analysis, we held prime-target name consistency constant (i.e., only same-name primes and targets were used), and prime-target case consistency and prime-target feature similarity (similar vs. dissimilar upper- and lowercase letters) were the main factors. Figure 4 shows the results of this analysis performed on the subset of letters defined by the visual similarity of their lower- and uppercase forms. There was a clear difference in the ERPs generated by targets preceded by same-case and different-case primes when the upper- and lowercase versions of letters were composed of different features (e.g., D-d, A-a). The same comparisons for letters that have similar features in their upper- and lowercase versions (e.g., C-c, S-s) produced relatively smaller differences in this time window. These effects of visual similarity, which started at about $100 \mathrm{msec}$ and extended to $200 \mathrm{msec}$, took

\section{Similar lower/upper letters $(\mathrm{C}-\mathrm{c})$}
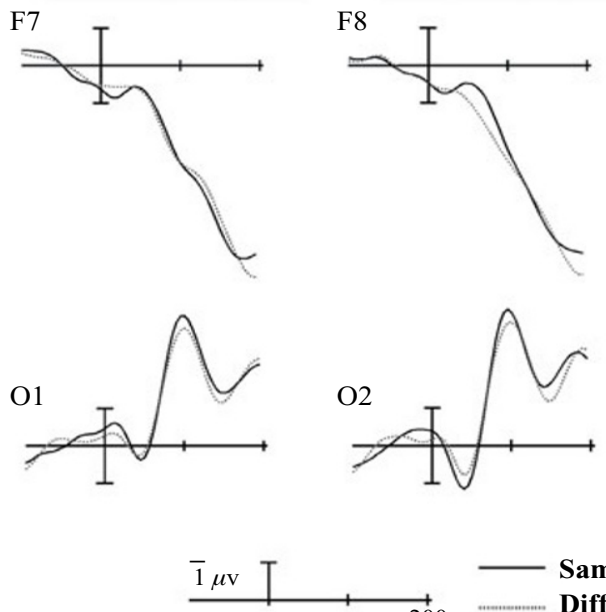
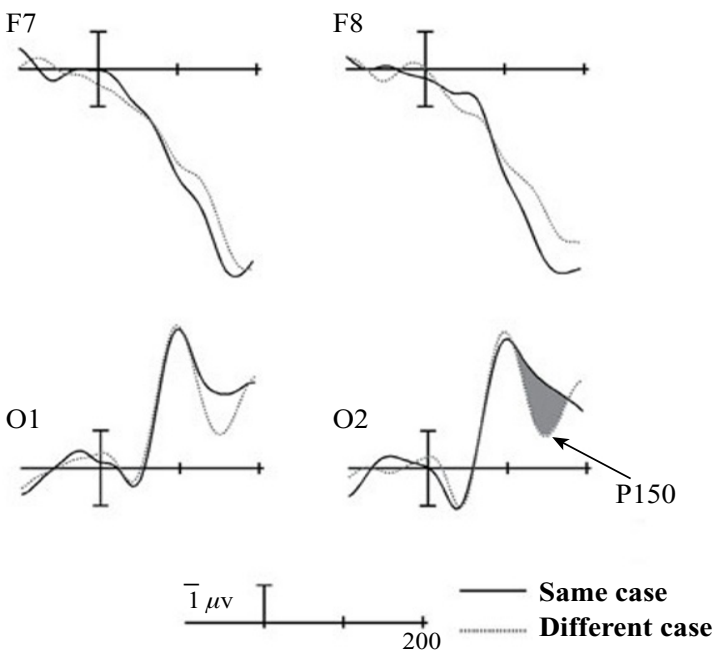

Figure 4. Target ERPs at two posterior and two anterior sites contrasting same-name letters that in their upper- and lowercase versions are either similar (left) or dissimilar (right). 
the form of a posterior positivity (P150) and an anterior negativity. These visual impressions were confirmed by a feature similarity $\times$ case consistency $\times$ electrode site interaction in the two most lateral columns of electrode sites $[\mathrm{C} 2, F(3,66)=4.04, p<.03 ; \mathrm{C} 3, F(4,88)=3.29$, $p<.048]$. Further follow-up analyses used to decompose this interaction revealed that the case $\times$ electrode site interaction was significant for dissimilar letters, but not for similar letters [dissimilar letters, $\mathrm{C} 2, F(3,66)=6.88, p<$ $.008 ; \mathrm{C} 3, F(4,88)=9.97, p<.001$; similar letter $F \mathrm{~s}<2$, see Table 1]. For dissimilar letters, a change in case from prime to target, relative to no change in case, produced more positive-going ERPs at the most lateral posterior sites $(\mathrm{O} 1 / 2$ and $\mathrm{T} 5 / 6)$, but more negative-going ERPs at the most lateral anterior sites (F7/8, F3/4, FC5/6). In line with our theoretical framework for letter perception, and in line with recent results obtained using masked priming and ERPs with word and object stimuli (Eddy et al., in press; Holcomb \& Grainger, 2006), we find a modulation of the P150 ERP component in occipital sites as a function of visual differences across prime and target.

\section{0- to 220-msec Epoch}

As can be seen in Figures 3A and 3B, between 180 and $220 \mathrm{msec}$, the time period surrounding the peak of the P200, targets preceded by different-letter primes in the same case (the solid blue line) were more positive-going than targets preceded by the same letter in the same case (the solid black line). This trend was most notable at midline and $\mathrm{C} 1$ sites and tended to trail off at more lateral sites. On the other hand, different-case targets (the red and green dashed lines) revealed no such differences. These impressions were borne out in the ANOVAs by significant case consistency $\times$ name consistency interactions in the midline and $\mathrm{C} 1$ analyses [midline, $F(1,22)=5.05$, $p<.035 ; \mathrm{C} 1, F(1,22)=6.26, p<.020 ; \mathrm{C} 2$ and $\mathrm{C} 3 F \mathrm{~s}<$ 1.2; see Table 1]. Follow-up simple effects tests indicated that there was a main effect of name consistency only when primes and targets were in the same case [midline, $F(1,22)=13.65, p<.001 ; \mathrm{C} 1, F(1,22)=11.80, p<$ $.002]$. None of the simple effects tests of name consistency were significant when primes and targets were in a different case (all $F \mathrm{~s}<1$ ). We interpret this interaction as reflecting the activation of case-specific letter representations that react mostly when primes are the same letter in the same case. This highly temporally localized reaction can be seen in Figure 3B, in which the waveform for the same-name/same-case condition is the only one to show a strong deflection starting around $180 \mathrm{msec}$.

\section{0- to 300-msec Epoch}

As can be seen in Figures 3A and 3B, between 220 and $300 \mathrm{msec}$ after the peak of the P200, targets preceded by different-letter primes in the same case continued to be more positive-going than targets preceded by sameletter primes in the same case. However, unlike the previous epoch, in which mixed-case targets revealed no significant differences, in this later epoch, there now ap- peared to be a notable difference between these conditions. Different-case targets that were different letter names than their primes (dashed green line) were more positivegoing than different-case targets that were the same letter name (dashed red line). ANOVAs in this epoch found main effects of name consistency across the scalp [midline, $F(1,22)=35.03, p<.001 ; \mathrm{C} 1, F(1,22)=25.26$, $p<.001 ; \mathrm{C} 2, F(1,22)=30.33, p<.001 ; \mathrm{C} 3, F(1,22)=$ $30.02, p<.001]$, but no significant evidence for a difference in the name consistency effect for same- vs. different-case letters (i.e., all name consistency $\times$ case consistency interactions, $F_{\mathrm{s}}<2$, see Table 1). Consistent with a widely distributed effect, name consistency did not interact with either hemisphere or electrode site in any of the analysis columns. We interpret this main effect of name consistency as reflecting activity in more abstract, case-independent letter representations, such that priming effects are not influenced by whether or not primes and targets are in the same case.

\section{DISCUSSION}

Guided by a model of the perceptual processes involved in letter processing, this experiment investigated the influence of prime-target name and case consistency on ERPs generated by letter targets in a masked priming paradigm. Early effects of visual similarity were also examined by performing separate analyses on letters with similar (e.g., c-C) or dissimilar (e.g., a-A) lower- and uppercase forms. All three priming manipulations had clear effects on the ERP waveforms, and the three manipulations showed distinct time courses. The pattern of effects provides support for the three-stage model of letter perception outlined in the introduction.

The initial analyses suggested that the effects of case consistency were the first to appear, emerging at around $100 \mathrm{msec}$ posttarget onset and peaking at $150 \mathrm{msec}$. Our preferred interpretation of this early and relatively widespread effect of case consistency is that it reflects activity in neural processes that are sensitive to large-scale physical changes in the stimulus, such as changes in size and orientation. As pointed out in note 1, the upper- and lowercase letters differed in size in the present study, so it is possible that it is a change in stimulus size that is driving the case consistency effect. Further experimentation is necessary in order to clarify the relative contribution of these different variables.

In the same time window, however, we also found clear evidence for a more localized effect of visual overlap across prime and target. This effect took the form of a larger positivity over the back of the head, especially at the right occipital electrode (i.e., P150), and a larger negativity over anterior sites, again especially over the right hemisphere. Although the inherent low spatial resolution of ERPs (Nunez, 1990) makes it difficult to know with certainty the exact source of the neural generator(s) for such an effect, it is tempting to speculate that this P150 modulation is being generated in or near visual cortical 
areas responsible for early visual feature processing. Exactly what this process is doing is still unclear, although in several recent studies using similar masked priming methodology, we have found similar effects with comparable scalp distributions, but using visual words (Holcomb \& Grainger, 2006) or pictures of simple objects (Eddy et al., in press). What these studies have in common is that the P150-eliciting events have features that do not match those of the immediately preceding masked prime, although the specific nature of these features is obviously very different across the studies. Consistent with the possibility that our P150 effect is indexing low-level visual feature analysis are a recent series of studies using MEG. These studies have shown early ( $100 \mathrm{msec})$ occipital activity that the authors argue is sensitive to low-level visual feature analysis (e.g., Cornelissen, Tarkiainen, Helenius, $\&$ Salmelin, 2003).

In the 180- to 220-msec epoch, the effects of case consistency significantly interacted with the effects of name consistency, such that whether or not primes were the same letter as targets only had an influence when primes and targets were in the same case. This effect was maximal in the region of the P200, where the waveforms generated by letter targets were more positive-going when primes were a different letter in the same case than when primes were the same letter in the same case. This pattern is interpreted as reflecting processing at the level of casespecific letter representations. When the prime stimulus is the same letter and in the same case as the target letter, prime processing leads to preactivation of the appropriate case-specific letter representation, hence modifying the subsequent processing of the target stimulus. When primes and targets are in a different case, different representations are involved at this particular stage of the letter identification process. These P200-centered effects were somewhat more broadly distributed than the earlier P150 effect, which makes speculation about the neural source(s) for this effect more difficult. MEG studies have shown effects in this same time frame (130 to $180 \mathrm{msec})$ that seem to be specific to the processing of letter strings (as opposed to noise or symbols) and localize primarily to left temporal-occipital regions. However, our P200centered effects were largest at midline and medial sites and showed no laterality effect.

Name consistency (the prime letter is the same as the target letter or not) had a systematic influence that was independent of case consistency starting around $220 \mathrm{msec}$ posttarget onset. Different-letter primes produced more positive-going waveforms compared with same-letter primes in the 220- to 300-msec epoch, and this effect did not depend on whether or not primes and targets were in the same case. This pattern is taken as evidence for processing at the level of abstract letter representations that are independent of letter case. Such case-independent letter representations would receive input from lower-level casedependent representations, thus explaining why their activity is reflected later on in the letter identification process.

In summary, the overall pattern of effects observed in the present study fits with the hierarchy of processing involved in letter perception that we outlined earlier in the article. According to this account, the effects of letter similarity/dissimilarity between 120 and $180 \mathrm{msec}$ reflect activity in an early process that is involved with extracting primitive features from the visual array before contact is made with letter representations. These visual features converge on case-specific letter representations such that the visual features associated with a lowercase "a," for example, connect up with the representation of the lowercase version of that letter but not with the representation of its uppercase version (although it remains to be seen whether highly similar lower- and uppercase forms already share a representation at this level). The interaction between name and case consistency found between 180 to $220 \mathrm{msec}$ is taken to reflect differential activation in such casespecific letter representations. Case-specific letter representations then feed information forward to more abstract, case-independent letter representations that are activated equally by lower- and uppercase versions of a given letter. The main effect of name consistency (that did not interact with case consistency) found between 220 and $300 \mathrm{msec}$ is thought to reflect activation at this level of processing. These high-level letter representations, which are relatively insensitive to variations in surface form, provide the gateway to phonological, articulatory, and conceptual information related to letter identities.

\section{REFERENCES}

Arguin, M., \& Bub, D. (1995). Priming and response selection processes in letter classification and identification tasks. Journal of Experimental Psychology: Human Perception \& Performance, 21, 1199-1219.

Bowers, J. S., Vigliocco, G., \& HaAn, R. (1998). Orthographic, phonological, and articulatory contributions to masked letter and word priming. Journal of Experimental Psychology: Human Perception \& Performance, 24, 1705-1719.

Cornelissen, P., Tarkiainen, A., Helenius, P., \& Salmelin, R. (2003). Cortical effects of shifting letter position in letter strings of varying length. Journal of Cognitive Neuroscience, 15, 731-746.

Dehaene, S., Cohen, L., Sigman, M., \& Vinckier, F. (2005). The neural code for written words: A proposal. Trends in Cognitive Sciences, 9, 335-341.

EdDy, M., Schmid, A., \& Holcomb, P. J. (in press). Masked repetition priming and event-related brain potentials: A new approach for tracking the time-course of object perception. Psychophysiology.

Greenhouse, S. W., \& Geisser, S. (1959). On methods in the analysis of profile data. Psychometrika, 24, 95-112.

Holcomb, P. J., \& Grainger, J. (2006). On the time-course of visual word recognition: An ERP investigation using masked repetition priming. Journal of Cognitive Neuroscience, 18, 1631-1643.

Holcomb, P. J., Reder, L., Misra, M., \& Grainger, J. (2005). The effects of prime visibility on ERP measures of masked priming. Cognitive Brain Research, 24, 155-172.

JaCOBS, A. M., \& Grainger, J. (1991). Automatic letter priming in an alphabetic decision task. Perception \& Psychophysics, 49, 43-52.

Jacobs, A. M., Grainger, J., \& Ferrand, L. (1995). The incremental priming technique: A method for determining within-condition priming effects. Perception \& Psychophysics, 57, 1101-1110.

Kiyonaga, K., Grainger, J., Midgley, K. J., \& Holcomb, P. J. (in press). Masked cross-modal repetition priming: An event-related potential investigation. Language \& Cognitive Processes.

McClelland, J. L., \& Rumelhart, D. E. (1981). An interactive activation model of context effects in letter perception: Part 1. An account of basic findings. Psychological Review, 88, 375-407. 
Misra, M., \& Holcomb, P. J. (2003). Event-related potential indices of masked repetition priming. Psychophysiology, 40, 115-130.

NUNEZ, P. L. (1990). Localization of brain activity with electroencephalography. Advances in Neurology, 54, 39-65.

Petit, J.-P., \& Grainger, J. (2002). Masked partial priming of letter perception. Visual Cognition, 9, 337-353.

SCHNYER, D. M., Allen, J. J. B., \& Forster, K. I. (1997). Event-related brain potential examination of implicit memory processes: Masked and unmasked repetition priming. Neuropsychology, 11, 243-260.

Selfridge, O. G., \& Neisser, U. (1960). Pattern recognition by machine. Scientific American, 203, 60-68.

Ziegler, J. C., Ferrand, L., Jacobs, A. M., Rey, A., \& Grainger, J. (2000). Visual and phonological codes in letter and word recognition: Evidence from incremental priming. Quarterly Journal of Experimental Psychology, 53A, 671-692.

\section{NOTE}

1. Given the design of the present study, the effect of case consistency could reflect differential sensitivity to lower- and uppercase letters appearing in either prime or target position, rather than an effect of change in case across prime and target stimuli. Furthermore, our manipulation of case was confounded with a change in stimulus size, since the lowercase letters were smaller than the uppercase letters. We are currently investigating these issues in ongoing work in our laboratory.

(Manuscript received June 4, 2005;

revision accepted for publication December 14, 2005.) 